\title{
Dissociative experiences in patients with epilepsy
}

\author{
Experiências dissociativas em pacientes com epilepsia \\ Osman Özdemir', Vedat Cilingir², Pınar Güzel Özdemir ${ }^{1}$, Aysel Milanlioglu², Mehmet Hamamci², Ekrem Yilmaz
}

\begin{abstract}
A few studies have explored dissociative experiences in epilepsy patients. We investigated dissociative experiences in patients with epilepsy using the dissociative experiences scale (DES). Ninety-eight patients with epilepsy and sixty healthy controls were enrolled in this study. A sociodemographic questionnaire and the Dissociative Experiences Scale (DES), Beck Depression Inventory (BDI) and Beck Anxiety Inventory (BAI) were administered to the participants. The DES scores were significantly higher for the patients with epilepsy than the healthy individuals. The number of individuals with pathological dissociation (DES $\geq 30$ ) was higher in the epilepsy group $(n=28)$ than in the control group $(n=8)$. Also, higher levels of dissociation were significantly associated with frequency of seizures, but were not associated with duration of epilepsy and age at onset of the disorder. These findings demonstrate that patients with epilepsy are more prone to dissociation than controls. The high rate of dissociative experiences among patients with epilepsy suggest that some epilepsy-related factors are present.
\end{abstract}

Keywords: dissociative experiences, epilepsy.

\section{RESUMO}

Poucos estudos exploraram as experiências dissociativas em pacientes com epilepsia. Investigamos as experiências dissociativas em pacientes com epilepsia através da Escala de Experiências Dissociativas (EED). Noventa e oito pacientes com epilepsia e 60 controles saudáveis foram incluídos neste estudo. Um questionário sócio-demográfico, a EED, o Beck Depression Inventory (BDI) e o Beck Anxiety Inventory (BAl) foram administrados aos participantes. Os valores de EED foram significativamente maiores nos pacientes com epilepsia em relação aos controles saudáveis. 0 número de indivíduos com doença dissociativa $(E E D \geq 30)$ foi maior no grupo de epilepsia $(n=28)$ todo que no grupo controle $(n=8)$. Além disto, altos níveis de dissociação estavam associados à frequência de crises epilépticas, mas não à duração da epilepsia ou idade de início da doença. Estes achados demonstram que pacientes com epilepsia são maus susceptíveis à dissociação do que os controles. 0 alto índice de experiências dissociativas entre os pacientes com epilepsia sugere que alguns fatores específicos da epilepsia possam estar relacionados aos achados.

Palavras-chave: experiências dissociativas, epilepsia.

Dissociative disorders are characterized by a disruption of and/or discontinuity in the normal integration of consciousness, memory, identity, emotion, perception, body representation, motor control, and behavior ${ }^{1}$. Dissociative experiences occur on a continuum ranging from the minor or normative dissociative states such as absorbtion or daydreaming customary to daily life to pathological states such as dissociative identity disorder ${ }^{2}$. The prevalence rates has varied from a low of $1.0 \%$ to a high of $12.8 \%$ depending on the cut-off point indicative of pathological dissociative symptomatology $y^{3,4}$. The Dissociative Experience Scale (DES) is the most widely used standard screening tool utilized for assessing dissociative symptoms $s^{3,4,5}$.
The strong linkages of dissociation to childhood emotional, physical or sexual trauma have long been recognized. Dissociation is considered to serve as a defense mechanism againts intolerable, trauma-associated memories and feelings ${ }^{4}$. Despite dissociative disorders are conceptualized in a separate spectrum, pathological dissociation has been demonstrated to be higly co-occurring condition with mental disorders including posttraumatic stress disorder, borderline personality disorders, anxiety and mood disorders, and substance use disorder ${ }^{4}$. Dissociative experiences can also be observed in different types of brain pathology such as epilepsy, head injuiry, tumor, encephalitis and intoxication ${ }^{6,7}$.

${ }^{1}$ Yuzuncu Yil University, Faculty of Medicine, Department of Psychiatry, Van, Turkey;

${ }^{2}$ Yuzuncu Yil University, Faculty of Medicine, Department of Neurology, Van, Turkey.

Correspondence: Osman Özdemir; Yuzuncu Yil University, Faculty of Medicine, Department of Psychiatry; Van 65200, Turkey; E-mail:drosmanozdemir@yahoo.com Conflict of interest: There is no conflict of interest to declare.

Received 24 August 2015; Received in final form 23 October 2015; Accepted 12 November 2015. 
It is known that complex partial seizures may resemble certain dissociative phenomena, e.g., altered sense of self and amnesia, fugue states, dissociative convulsions, and disturbed consciousness ${ }^{3,6,8}$. The symptoms of depersonalization/derealization associated with the temporal or frontotemporal EEG abnormalities responding to anticonvulsant treatment have been reported ${ }^{6}$. Also, dissociative disorders are more common in patients with epilepsy than in the general population (range from 5 to $40 \%$ versus 0.3 to $3.4 \%)^{3}$. The higher prevalence of dissociative experiences may suggest an association between epilepsy and dissociation. Epilepsy can increase one's susceptibility to developing dissociative experiences ${ }^{3}$.

Devinsky et al. ${ }^{9}$ investigated the possible relationship between dissociative states and epilepsy. They used video-EEG monitoring to determine whether the patients have epileptic epizodes in 6 multiple personality disorder (MPD) patients with previously diagnosed with epilepsy; however, none proved to have epilepsy. In addition, they studied dissociative symptoms in 71 epileptic patients and age-matched normal controls. The mean DES score was higher in cases with complex partial seizures than in controls, and was significantly lower than that of the patients with MPD. Partial seizure patients with dominant hemisphere foci had higher depersonalization subscale scores than those with nondominant foci. The authors suggest that epilepsy is not a primary pathophysiologic mechanism for developing dissociative symptoms.

Once again, Devinsky et al. ${ }^{10}$ compared the experience of dissociative symptoms in patients with focal and primary generalized epilepsy and control subjects. Ictal depersonalization was observed in $15 \%$ of patients with partial seizures, occuring interictally in $10 \%$. This symptom was reported by $3 \%$ of healthy control subjects but by none of the patients with primary generalized seizures. They found that derealization was more commonly seen among patients with complex partial seizures during ictal as well as interictal periods than controls (18\%, $14 \%$ and $12 \%$, respectively). However, derealization was present in only $5 \%$ of patients primary generalized epilepsy. Different forms of dissociation such as distortions of shape, size, and distance of objects were reported by patients with epilepsy but were not reported by control group.

Psychogenic nonepileptic seizures (PNES) is characterized by a sudden onset and time limited disturbance in controlling motor, sensory, autonomic, cognitive, emotional, and behavioral functions resembling dissociative disorders ${ }^{11}$. Several studies have investigated the relationship between PNES and epilepsy ${ }^{5,12}$. It has been reported that PNES occur about $20 \%$ in patients with epilepsy ${ }^{11}$. A number of studies have found elevated levels of dissociation in patients with PNES $^{13,14}$. Patients with PNES often experience dissociative symptoms, increased dissociative tendency and high hypnotisability. Some authors argued that dissociation underlies the psychopathology of PNES ${ }^{13}$. These findings suggest that epilepsy is associated with dissociation.

Akyüz et al. ${ }^{15}$ studied dissociative experiences, childhood abuse and anxiety in epileptic and pseudoseizure female patients ${ }^{15}$. Both pseudoseizure and epileptic seizure groups had DES scores greater than those of normal adult subjects. In addition, DES scores of the pseudoseizure group were statistically higher than the epileptic group. In another study, the DES was administered to patients with epilepsy and PNES, patients with epilepsy and no PNES and healthy control individuals by Ito et al. ${ }^{5}$ The authors found that patients with epilepsy and PNES scored significantly higher on the DES than patients with epilepsy without PNES and nonclinical individuals. Alper et al. ${ }^{16}$ examined the dissociation in patients with complex partial epilepsy (CPE) and PNES. There were no significant differences in total DES scores between the two groups. PNES and CPE patients both had DES scores greater than those of normal adult subjects and less than those of subjects with dissociative disorders.

Several studies have shown that PNES are commonly in patients with epilepsy. In contrast, relatively few studies have investigated dissociative experiences in epilepsy patients. The results of some studies showed higher levels of dissociation in patients with epilepsy. However, others have found no correlation between epilepsy and dissociation. In the recent past, Hara et al. ${ }^{3}$ investigated dissociative experiences in 225 patients with epilepsy and 334 nonclinically matched individuals using the DES ${ }^{3}$. They found that there was no significant difference in the DES score between the group with epilepsy and the control group. Similarly, Wood et al. ${ }^{17}$ found no difference in the DES scores between patients with psychogenic seizures and with epilepsy. Because of the contradictory findings, further studies are needed to understand the linkages between dissociative experiences and epilepsy. In this study we aimed to investigate dissociative experiences in patients with epilepsy.

\section{METHOD}

\section{Subjects}

The subjects consisted of 98 patients with epilepsy and 60 healthy controls. Patients were selected from consecutive admissions to the neurology department of the hospital according to the following criteria: (1) epilepsy type either generalized epilepsy or focal epilepsy (2) age at the time of evaluation ranging from 15 to 70 years; (3) no history of psychosis, substance abuse, dementia, or progressive neurological disease and (4) no clinically significant signs of other psychiatric disorders requiring treatment (such as depression and anxiety disorders) at the time of the evaluation. All the patients were diagnosed using video-EEG technique as per the International League Against Epilepsy (ILAE) classification. Magnetic resonance imaging (MRI) was 
used to diagnose the structural lesion. The control group was age-and education- matched with the group with epilepsy.

\section{Instrument}

Socio-Demographic Questionnaire: The Sociodemographic questionnaire included questions about age, marital status, educational level, employment status, duration of epilepsy, age of epilepsy onset, and frequency of seizures.

Dissociative Experiences Scale (DES): The Dissociative Experiences Scale is a 28-item self-report questionnaire developed for screening dissociative experiences including disturbances in memory, identity, awareness, and cognition, not occurring under the influence of alcohol or drugs. The possible response options increase by increments of $10 \%$ ("this never happens") to $100 \%$ ("this always happens"). The Turkish version of the DES was demonstrated to have good reliability and validity almost equal to its original form ${ }^{18}$.

Beck Depression Inventory (BDI): The Beck Depression Inventory (BDI) is a 21-item self-report measure of depressive symptom severity. Each item israted on a 0-3 and the total scores range from 0 to 63 . The validity and reliability Turkish version of the BDI was demonstrated by Hisli' ${ }^{19}$.

Beck Anxiety Inventory (BAI): The Beck Anxiety Inventory (BAI) consists of twenty-one items self report used to assess emotional, physiological, and cognitive symptoms of anxiety. Multiple choices questions have four possible answers: not at all (0 points), mildly ( 1 points), moderately ( 2 points), and severely ( 3 points). The test scores range between 0 and 63 . The validity and reliability Turkish version of the BAI was performed by Ulusoy et al. ${ }^{20}$.

\section{Procedure}

The study received approval from the University Ethical Committee. Each participant written informed concent form. The DES, BDI, and BAI was administered to all the individuals of the two groups. We studied and compared the dissociative experiences and depression and anxiety levels between patients suffering from epilepsy and healthy controls. The group with epilepsy was further divided into according to EEG pattern of epileptiform activity groups for analysis.

\section{Statistical analysis}

Descriptive statistics for continuous variables were presented as mean and standard deviation. Student t-test was used to compare group means for the studied variables. Chi-square test was carried out to examine relationships between groups and categorical variables. Statistical significant level was considered as $\mathrm{p}<0.05$. The SPSS (ver. 16) statistical program was used for statistical analyses.

\section{RESULTS}

The mean age at first epileptic seizure was 16.2 years (standard deviation (SD) 7.8). Duration of epilepsy was 108.3 months (SD 124.1). The median seizure frequency was 71.0 seizures/year (SD 146.0).

Comparison of age, gender, BAI, BDI and Dissociative Experiences Scale scores of the group with epilepsy and the healthy controls shown in Table 1. The mean age of patients was 25.3 years (SD 10.2), and the mean age of controls was 27.9 years (SD 4.3). There were no statistically significant differences in the age and gender between the two groups $(\mathrm{p}>0.05)$. Patients with epilepsy scored significantly higher mean scores on the DES, BAI and BDI compared to control group ( $\mathrm{p}<0.01$ ). Additionally, subjects with pathological dissociation (DES $\geq 30$ ) was greater in epilepsy groups than in control group ( $p<0.05)$. Twenty-eight epilepsy patients (28.5\%) and 8 healthy individuals (13.3\%) had pathological dissociation.

Comparison of age at onset of disease, duration of epilepsy and frequency of seizures between epilepsy patients with and without pathological dissociation are presented in Table 2. No significant differences between patients with pathological dissociation $(n=28)$ and patients without pathological dissociation $(n=70)$ were found in age at onset and duration of epilepsy. Frequency of seizures was significantly higher in the patients with pathologic dissociation compared to patients without pathological dissociation $(\mathrm{p}<0.05)$.

Comparison of DES scores in groups with epilepsy according to EEG pattern of epileptiform activity are shown in Table 3. The patients were divided into groups: generalized

Table 1. Comparison of age, gender, Beck Anxiety Inventory (BAI), Beck Depression Inventory (BDI) and Dissociative Experiences Scale (DES) scores of the group with epilepsy and the control group.

\begin{tabular}{|c|c|c|c|}
\hline & & & \\
\hline & $\begin{array}{l}\text { Epilepsy patients } \\
\qquad(\mathrm{n}=98)\end{array}$ & $\begin{array}{l}\text { Healthy controls } \\
\qquad(n=60)\end{array}$ & $p$-value \\
\hline Age & $25.3 \pm 10.2$ & $27.9 \pm 4.3$ & 0.066 \\
\hline Gender male /female & $47 / 51$ & $27 / 33$ & 0.717 \\
\hline DES & $23.8 \pm 17.8$ & $15.0 \pm 10.6$ & $0.001 * *$ \\
\hline BAl & $24.7 \pm 13.2$ & $12.0 \pm 9.4$ & $0.000 * *$ \\
\hline $\mathrm{BDI}$ & $20.4 \pm 11.2$ & $9.9 \pm 6.6$ & $0.000 * *$ \\
\hline$D E S \geq 30$ & $28(28.5 \%)$ & $8(13.3 \%)$ & $0.016^{*}$ \\
\hline
\end{tabular}

SD: standard deviation; ${ }^{\star} p<0.05 ;{ }^{*} p<0.01$ 
Table 2. Comparison of age at disease onset, seizure frequency and duration of epilepsy in the epilepsy patients who has pathologic dissociation (DES $\geq 30$ ) and who has not

\begin{tabular}{lccc}
\hline & \multicolumn{3}{c}{ Mean \pm SD } \\
\cline { 2 - 3 } & $\begin{array}{c}\text { DES } \geq 30 \\
(n=28)\end{array}$ & $\begin{array}{c}\text { DES }<30 \\
(n=70)\end{array}$ & p-value \\
\hline Age of epilepsy onset & $17.6 \pm 6.8$ & $16.0 \pm 7.9$ & 0.376 \\
Duration of epilepsy & $85.6 \pm 96.4$ & $120.4 \pm 133.2$ & 0.238 \\
Frequency of seizures & $126.7 \pm 226.0$ & $49.7 \pm 94.1$ & $0.021^{\star}$ \\
\hline
\end{tabular}

DES: Dissociative experiences scale; SD: standard deviation; ${ }^{p}<<0.05$

epileptiform activity $(\mathrm{n}=34)$ and focal epileptiform activity $(\mathrm{n}=34)(\mathrm{p}=0.914)$, right hemisphere $(\mathrm{n}=14)$ and left hemisphere $(\mathrm{n}=20)(\mathrm{p}=0.426)$, temporal epileptiform activity $(\mathrm{n}=10)$ and frontal epileptiform activity $(\mathrm{n}=9)(\mathrm{p}=0.761)$. There were no statistically significant differences among the groups with respect to DES scores.

\section{DISCUSSION}

In the current study, we found that the DES scores were significantly higher in the patient with epilepsy than in the healthy individuals. The number of individuals with pathologic dissociation (DES $\geq 30$ ) was higher in the patients group than in the control group. In addition, higher levels of dissociation were significantly associated with frequency of seizures, but were not associated with duration of epilepsy and age at onset of the disorder. The DES scores did not differ significantly with respect to the various EEG parameters such as generalized or focal, right or left sided, and temporal or frontal lobes epileptic activity. These findings suggest that patients with epilepsy are more prone to experiencing dissociation. The high rate of dissociative experiences in patients with epilepsy suggests some epilepsy-related factors precipitating and maintaining dissociation. These predisposing risk factors could also be potential shared aetiological, neurobiological mechanisms that may cause both epilepsy and dissociation.

There has been growing evidence for linkages between dissociation and epilepsy. Ito et al. ${ }^{5}$ reported that patients with epilepsy and PNES had significantly higher DES and DES taxon (DES-T; a subset of DES score and an index of pathological dissociation) scores than nonclinical

Table 3. Comparison of Dissociative Experiences Scale (DES) scores in groups with epilepsy according to EEG pattern of epileptiform activity.

\begin{tabular}{lcc} 
& DES & $p$-value \\
\hline Generalized $(n=34)$ & $23.47 \pm 18.34$ & 0.914 \\
Focal $(n=34)$ & $23.02 \pm 15.23$ & \\
Right hemisphere $(n=14)$ & $20.50 \pm 14.39$ & \\
Left hemisphere $(n=20)$ & $24.80 \pm 15.90$ & 0.426 \\
Temporal $(n=10)$ & $20.60 \pm 13.04$ & \\
Frontal $(n=9)$ & $23.00 \pm 20.35$ & 0.761 \\
\hline
\end{tabular}

individuals. In addition, high DES scores (> 30) were more frequently observed in patients with epilepsy and PNES than in patients with epilepsy without PNES and nonclinical individuals. DES score did not differ significantly with respect to epilepsy-related variables including age at onset of epilepsy, duration of epilepsy, types of epilepsy determined on the basis of ictal symptoms and EEG and neuroimaging findings. Consistent with this research findings, we found no significant differences between the high and low dissociation groups (cutoff score of 30) in terms of duration of epilepsy and age of epilepsy onset.

Hara et al. ${ }^{3}$ showed a significantly higher DES-T and DES score $\geq 30$ (two indices for pathological dissociation) in the group with epilepsy than the control group. On the other hand, these pathological dissociation were significantly associated with duration of epilepsy and seizure frequency. Duration of epilepsy correlated inversely with both the DES scores and DES-T. Seizure frequency correlated with the DES-T but not with the DES scores. The authors argued that the distress with frequent seizures and uncertainties of the occurence of epileptic seizures may make patients with epilepsy more prone to dissociation. In addition, as age advances, seizure frequency tends to decrease as well as with age advancing, the DES indices decreased. In our study, we observed that the patients who experience more seizure tend to have pathological dissociation. Our results also demonstrated the presence of significantly increased incidence of pathological dissociation (DES $\geq 30$ ) in patients with epilepsy as compared with the control group. Twenty eight (28.5\%) of the 98 patient with epilepsy and eight of the control (13.3\%) had DES scores of 30 or above $(p=0.021)$.

The etiology of this high prevalence of dissociative experiences in patients with epilepsy remains unclear. Wang et al. ${ }^{21}$ have tried to find an answer from the neuropathological and sociodemographic perspectives. The authors found that dissociative experiences were more prevalent in the patients with epilepsy. Moreover, the dissociative experiences in patients with epilepsy are not related to the neuropathological features such as location of lesion (temporal, frontal, other lesion), presence or absence mesial temporal lobe epilepsy, side of lesion (rihgt, left, both sides, no lesion), and type of seizure (focal seizures, focal with secondary generalization, generalized tonic-clonic seizures). DES scores are related to the sociodemographic parameters similar to those of the general 
population. There was a higher dissociative symptoms in female, lower education and low socioeconomic status.

Mula et al. ${ }^{7}$ investigated whether there is an association between EEG lateralization and DES scores. They did not find any difference in DES scores across different lateralities (right/left or monolateral/bilateral). Hara et al. ${ }^{3}$ found no link between dissociation and epilepsy types (temporal, frontal, parietal, occipital and partial epilepsy with undetermined lobar foci), the presence of either mesial temporal sclerosis or laterality of EEG abnormalities (left, right, bilateral). In our relatively small sample, we found no significant difference in DES scores between patients who had focal $(n=34)$ and generalized $(n=34)$, right $(n=14)$ and left sided $(n=20)$, or temporal lobes $(n=10)$ and frontal lobes $(n=9)$ epileptiform activity. The results appear to indicate lack of relation between dissociation and EEG localization regarding to epileptiform activity.

On the other hand, previous studies also showed that patients with temporal lobe epilepsy (TLE) experience several dissociative symptoms such as out of body experiences, near death experiences, depersonalization and fugue $e^{6,7,22,23,24}$. Connections of EEG abnormalities with several dissociative syndromes including dissociative identity symptoms have been described ${ }^{22,24}$. Temporal lobe epileptiform discharges and the limbic structures which are essential regions for generation of complex partial seizures can lead to these symptoms ${ }^{3,21,22}$. Devinsky et al. ${ }^{10}$ found that depersonalization was associated with complex partial ( focal) epilepsy rather than primary generalized epilepsy. Kuyk et al..$^{25}$ found higher dissociation in patients with TLE than nonclinical individuals. Devinsky et al. ${ }^{26}$ reported PNES groups (PNES only and PNES plus epilepsy) have a significantly higher frequency of right hemisphere pathology compared with patients with epilepsy (without PNES or any other psychiatric disorders). The authors have found the manifestation of conversion disorder to be more common in right hemisphere lesions supporting the mechanism of right hemisphere dysfunction.

In the recent years, despite the enormous amount of clinical, experimental, and theoretical interest in this area, the neurobiological basis of dissociation is still poorly understood. Functional disconnectivity syndrome has been assumed to explain the dissociative symptoms. The authors investigated the hypothesis that a dysfunction of hemispheric interaction might be a predisposition to dissociative psychopathology ${ }^{27,28}$. Spitzer et al. $^{27}$ examined the relationship between dissociation and interhemispheric structural asymmetry. The researchers have found that the high dissociators (DES scores $\geq 30$ ) had a significantly lower left hemispheric excitability than righ hemispheric excitability. Ashworth et al. ${ }^{28}$ demonstrated that participants scoring high in dissociation displayed left hemispheric lateralization. These findings suggest that dissociation involves a cortical asymmetry with a left hemispheric superiority or, alternatively, a lack of right hemispheric interaction ${ }^{27}$. Thus, an altered feelings of familiarity, depersonalization and derealization symptoms, may be linked to the right hemisphere dysfunction. The functional deficits in the sensorimotor and cognitive processes may play a crucial role in dissociation ${ }^{28}$.

The relationship between epilepsy and dissociation is complex and some authors have argued that dissociative experiences in epilepsy are often associated with comorbid anxiety ${ }^{7}$. One theoretical view argued that dissociative reactions are associated with extremely elevated psychological and physiological arousal state that occurs during a anxiety $^{29}$. Sterlini and Bryant ${ }^{29}$ described that extent anxiety and marked physiological arousal are strongly predictive peritraumatic dissociation that occur during or immediately after a traumatic event. Further, dissociative symptoms are commonly experienced during panic attacks. Mula et al. ${ }^{7}$ observed no difference in DES scores between patients with or without auras, but DES scores correlated with the anxiety scores. In our study, BAI scores of patients with epilepsy were significantly higher compared to the than control group $(\mathrm{p}=0.000)$.

Taken together, our findings and other evidences might suggest that dissociative experiences are more common in patients with epilepsy than in healthy controls. It appears that this dose not result from localization related epilepsy. In contrast, some previous studies showed that dissociative phenomena are associated with temporal lobe epilepsy and the complex partial seizures ${ }^{3,21}$. These contradictory findings warrant further studies with large representative samples. 
1. American Psychiatric Association. Diagnostic and statistical manual of mental disorders. 5th ed. Arlington: American Psychiatric Publishing; 2013.

2. Özdemir O, Özdemir PG, Boysan M. The relationships between dissociation, attention, and memory dysfunction. Arch Neuropschiatry. 2015;52:36-41. doi:10.5152/npa.2015.7390

3. Hara K, Adachi N, Akanuma N, Ito M, Okazaki M, Matsubara R et al. Dissociative experiences in epilepsy: effects of epilepsy-related factors on pathological dissociation. Epilepsy Behav. 2015;44:185-91. doi:10.1016/j.yebeh.2014.12.018

4. Maaranen P, Tanskanen A, Honkalampi K, Haatainen K, Hintikka J, Viinamäki $H$. Factors associated with pathological dissociation in the general population. Aust N Z J Psychiatry. 2005;39(5):387-94. doi:10.1080/j.1440-1614.2005.01586.x

5. Ito M, Adachi N, Okazaki M, Kato M, Onuma T. Evaluation of dissociative experiences and the clinical utility of the Dissociative Experiences Scale in patients with coexisting epilepsy and psychogenic nonepileptic seizures. Epilepsy Behav. 2009;16(3):491-4. doi:10.1016/j.yebeh.2009.08.017

6. Lambert MV, Sierra M, Phillips ML, David AS. The spectrum of organic depersonalizaton: a review plus four new cases. J Neuropsychiatry Clin Neurosci. 2002;14(2):141-54. doi:10.1176/jnp.14.2.141

7. Mula M, Cavanna A, Collimedaglia L, Barbagli D, Magli E, Monaco F. The role of aura in psychopathology and dissociative experiences in epilepsy.J Neuropsychiatry Clin Neurosci. 2006;18(4);536-42.

8. Medford N. Dissociative symptoms and epilepsy. Epilepsy Behav. 2014;30:10-13. doi:10.1016/j.yebeh.2013.09.038

9. Devinsky O, Putnam F, Grafman J, Bromfield E, Theodore WH. Dissociative states and epilepsy. Neurolog.y 1989;39(6):835-40. doi:10.1212/WNL.39.6.835

10. Devinsky O, Feldmann E, Bromfield E, Emoto S, Raubertas R. Structured interview for partial seizures: clinical phenomenology and diagnosis. J Epilepsy. 1991;4(2):107-16. doi:10.1016/S0896-6974(05)80069-6

11. Prueter C, Schultz-Venrath U, Rimpau W. Dissociative and associated psychopathological symptoms in patients with epilepsy, pseudoseizures, and both seizure forms. Epilepsia. 2002;43(2):188-92. doi:10.1046/j.1528-1157.2002.45900.x

12. Bautista RE, Gonzales-Salazar W, Ochoa JG. Expanding the theory of symptom modeling in patients with psychogenic nonepileptic seizures. Epilepsy Behav. 2008;13(2):407-9. doi:10.1016/j.yebeh.2008.04.016

13. Kruijs SJ, Jagannathan SR, Bodde NM, Besseling RM, Lazeron $\mathrm{RH}$, Vonck KE et al. Resting-state networks and dissociation in psychogenic non-epileptic seizures.J Psychiatr Res. 2014;54:126-133. doi:10.1016/j.jpsychires.2014.03.010

14. Lawton G, Baker GA, Brown RJ. Comparison of two types of dissociation in epileptic and nonepileptic seizures. Epilepsy Behav. 2008;13(2):333-6. doi:10.1016/j.yebeh.2008.04.015
15. Akyuz G, Kugu N, Akyuz A, Dogan O. Dissociation and childhood abuse history in epileptic and pseudoseizure patients Epileptic Disord. 2004;6(3):187-92.

16. Alper K, Devinsky O, Perrine K, Luciano D, Vazquez B, Pacia $S$ et al. Dissociation in epilepsy and conversion nonepileptic nonepileptic seizures. Epilepsia. 1997;38(9):991-7. doi:10.1111/j.1528-1157.1997.tb01481.x

17. Wood BL, McDaniel S, Burchfiel K, Erba G. Factor distinguishing families of patients with psychogenic seizures from families of patients with epilepsy. Epilepsia. 1998;39(4):432-7. doi:10.1111/j.1528-1157.1998.tb01396.x

18. Yargic LI, Tutkun H, Sar V. The reliability and validity of the Turkish version of the dissociative experiences scale. Dissociation. 1995;8:10-13.

19. Hisli N. The validity and reliability of the Beck Depression Inventory among university students. Turkish J Psychol. 1989;7:3-13.

20. Ulusoy M, Șahin N, Erkmen H. Turkish version of the Beck Anxiety Inventory. J Cognitive Psychother. 1998;12(2):163-72.

21. Wang YG, Li Z, Zhang W, Prakash R. Dissociative experiences in epilepsy- a neuropathological and sociodemographic study in a Chinese population. Epilepsy Behav. 2014;37:287-90. doi:10.1016/j.yebeh.2014.05.028

22. Bob P. Dissociation and neuroscience: history and new perspectives. Int J Neurosci 2003;113(7):903-14. doi:10.1080/00207450390220376

23. Bob P. Dissociation and neurobiological consequences of traumatic stress. Act Nerv Sup (Praha). 2008;50(1-2):9-14.

24. Hersh J, Chan YC, Smeltzer D. Identity shifts in temporal lobe epilepsy. Gen Hosp Psychiatry. 2002;24(3):185-7. doi:10.1016/S0163-8343(02)00173-1

25. KuykJ, Spinhoven P, Emde Boas W, Dyck R. Dissociation in temporal lobe epilepsy and pseudo-epileptic seizure patients. J Nerv Ment Dis. 1999;187(12):713-20. doi:10.1097/00005053-199912000-00002

26. Devinsky O, Mesad S, Alper K. Nondominant hemisphere lesions and conversion nonepileptic seizures. J Neuropsychiatry Clin Neurosci. 2001;13(3):367-73. doi:10.1176/jnp.13.3.367

27. Spitzer C, Willert C, Grabe HJ, Rizos T, Möller B, Freyberger HJ. Dissociation, hemispheric asymmetry and dysfunction of hemispheric interaction: a transcranial magnetic stimulation approach.J Neuropsychiatry Clin Neurosci. 2004;16(2):163-9. doi:10.1176/jnp.16.2.163

28. Ashworth J, Ciorciari J, Stough C: Psychophysiological correlates of dissociation, handedness, and hemispheric lateralization. J Nerv Ment Dis. 2008;196(5):411-6. doi:10.1097/NMD.0b013e31816ff384

29. Sterlini GL, Bryant RA. Hyperarousal and dissociation: a study of novice skydivers. Behav Res Ther. 2002;40(4):431-7. doi:10.1016/S0005-7967(01)00021-3 